\title{
Physiological and Biochemical Characterization of a Red Escarole Obtained from an Interspecies Crossing
}

\author{
Alessandro Natalini ${ }^{1}$, Giacomo Cocetta ${ }^{2, *(D)}$, Nazzareno Acciarri ${ }^{3}$ and Antonio Ferrante $^{2}$ (D) \\ 1 ISI Sementi SpA Frazione Ponte Ghiara, 8, 43036 Fidenza, Italy; alessandro.natalini@isisementi.com \\ 2 Department of Agricultural and Environmental Sciences-Production, Landscape, Agroenergy, \\ Università Degli Studi Milano, Via Celoria 2, 20133 Milan, Italy; antonio.ferrante@unimi.it \\ 3 Consiglio per la ricerca in agricoltura e l'analisi dell'economia agraria-Research Centre for Vegetable \\ and Ornamental Crops, Via Salaria 1, 63077 Monsampolo del Tronto, Italy; nazzareno.acciarri@crea.gov.it \\ * Correspondence: giacomo.cocetta@unimi.it; Tel.: +39-02-503-16593
}

Received: 9 April 2018; Accepted: 11 April 2018; Published: 16 April 2018

\begin{abstract}
Escarole (Cichorium endivia L.) and radicchio (Cichorium intybus L.) are two important leafy vegetables appreciated by consumers for their sensory attributes, and at the same time, they can be considered a good source of health-promoting secondary metabolites, including polyphenols, flavonoids, and anthocyanins. The aim of this work is the characterization of a new variety of red escarole obtained after a long-term breeding program involving the interspecies crossing between red radicchio and green escarole. Our multidisciplinary approach of investigation allowed us to study the effects of the crossing on several aspects, including the accumulation of phenolic compounds and anthocyanins, the expression pattern of some of the key genes in the phenylpropanoid pathway, and the sensory profiling of the new variety obtained. Given the results, it is possible to conclude that the new variety of red escarole presents traits deriving from both radicchio and escarole. The sensory profile and the preliminary data on yield, suggests that red escarole has interesting characteristics that could be successfully introduced into the market of leafy crops.
\end{abstract}

Keywords: anthocyanins; chicory; gene expression; phenolic compounds; sensory analysis

\section{Introduction}

Phenolic compounds and, in particular, anthocyanins are secondary metabolites, which have an important role in both plants and human cells. In plants, phenolic compounds and phenolic pigments have an important ecological role, as they are implicated in plant allelopathy [1] and in the interactions of plants with animals and soil [1]. Polyphenols act in plant signaling and in the response to biotic and abiotic stresses. In fact, stressful conditions can significantly affect phenolic metabolism and, in turn, the quality of fruits and vegetables [2,3]. In recent years, these molecules have been largely studied for their positive effects on human health [4]. It has been hypothesized that their effect on humans is mostly related to their antioxidant and anti-inflammatory properties [5]. However, recent studies have suggested that more clinical trials should be performed to assess the in vivo efficacy of these molecules and to better characterize their mechanisms of action in humans [6]. The biosynthesis of phenolic compounds occurs through the phenylpropanoid pathway. This metabolic route is regulated by several enzymes, and it is affected by a combination of many factors, such as genotype, environment, and agronomic management [7-9]. Red chicory or red radicchio (Cichorium intybus L.) is a leafy vegetable that is particularly rich in anthocyanin pigments that give its leaves a characteristic dark red coloration. Given this peculiar trait, red radicchio is largely used as a component of ready-to-eat mixed salads, and it is very appreciated by consumers, because this color has often been associated with beneficial health properties in foods [10]. The regulation of the 
different branches of the phenylpropanoids biosynthetic pathway can be exploited for improving the visual aspect, the attractiveness, and, at the same time, the nutraceutical value of phenolics-rich foods [11]. The aim of this study is to characterize a new line of red escarole (RE) obtained from an interspecies crossing between red radicchio (RR) and green escarole (GE) to improve the anthocyanin content of escarole, obtaining new nutraceutical and sensory features. This work is mainly focused on the alterations in the phenylpropanoid pathway deriving from the crossing. In detail, the levels of total phenolic compounds and total anthocyanins were measured and compared to the changes in the expression of some of the key genes in their biosynthetic route. Moreover, a detailed sensory evaluation was conducted to assess the new line acceptability and its appreciation by the consumers.

\section{Materials and Methods}

This line of red escarole is of the Innova variety (ISI Sementi, Fidenza, Italy) and was obtained by the initial crossing of two parental lines, Cichorium endivia L. $\times$ Cichorium intybus L., as female (GE, plain type) and male (RR) lines, respectively. This selective breeding program has been conducted for more than 10 years in order to improve the quantitative and qualitative traits on the segregated genotypes. In addition, molecular techniques have been applied on the most promising genotypes to reach stability and uniformity. The whole breeding program has been conducted in plot fields randomly distributed ( $n=3,100$ plants/plot) according to commercial requirements. At the end of the breeding, a stable and uniform line of RE was obtained and registered (AND 257, NL; PVP $n$. 2013/1839). The varieties GE and RR used in this experiment are the parental lines initially used to constitute the variety of RE.

The plants used in this experiment were grown in an area traditionally dedicated to autumn and winter leafy crops cultivation, located in Sala di Cesenatico, Cesena, Italy $\left(44^{\circ} 09^{\prime} 17^{\prime \prime} \mathrm{N} 12^{\circ} 23^{\prime} 05^{\prime \prime} \mathrm{E}, 10 \mathrm{~m}\right.$ altitude). Approximatively 1000 of the four-week-old plantlets of RE, RR, and GE were transplanted on 10 September 2016 in a $0.35 \mathrm{~m} \times 0.35 \mathrm{~m}$ plant density. The plants were grown under commercial conditions until the harvesting day on 1 December 2016, corresponding to the commercial maturity day for all the varieties. All the varieties were grown in three fields located in the same geographical area (to avoid environmental interfering factors) with 1000 plants of each genotype. Biological replications were randomly harvested from an area of $450 \mathrm{~m}^{2}$, and samples were randomly collected. The cultivation soil used for the three varieties had the same chemical-physical characteristics. Once collected, the samples for biochemical and molecular analysis were immediately immersed into liquid nitrogen and freeze-dried. In order to consider the fluctuations in gene expression due to environmental factors, the samples for the molecular analyses were collected at two time points: at 8 a.m. and 11 a.m. The samples for the sensory evaluation were gently washed in chlorinated water $\left(50 \mu \mathrm{L} \mathrm{L}^{-1}\right)$, rinsed, and cold-stored $\left(5 \pm 1{ }^{\circ} \mathrm{C}\right)$ overnight in dark conditions. At harvest, five whole heads of each variety were collected and weighed without roots and solid fractions by using a professional precision spring scale (model Macro Line, Pesola AG, Schindellegi, Switzerland).

Samples of the frozen tissue $(100 \mathrm{mg})$ of RE, RR, and GE were ground in a pre-chilled mortar and extracted into acidified methanol ( $\mathrm{HCl} 1 \%)$. The samples were incubated overnight at $4{ }^{\circ} \mathrm{C}$ in the dark. The extracts obtained were read by a spectrophotometer using a scan length range from 300 to $600 \mathrm{~nm}$ to evaluate the differences in the absorbance of phenols and leaf pigments (mainly carotenoids and anthocyanins). Total phenolics were determined using two methods: with a direct absorbance reading at $320 \mathrm{~nm}$ and with a Folin-Ciocalteu reagent. In the direct method, the total phenols were estimated by measuring absorbance at $320 \mathrm{~nm}$ using an UV-Vis spectrophotometer [12]. The total phenols in the extracts were assayed using the Folin-Ciocalteu method. The readings of the reactions containing $0.200 \mathrm{~mL}$ extract and $0.5 \mathrm{~mL}$ Folin-Ciocalteu (Sigma-Aldrich, Milan, Italy) reagent plus water up to $10 \mathrm{~mL}$ were performed at $760 \mathrm{~nm}$ after $2 \mathrm{~h}$ incubation at room temperature [13]. The total anthocyanins were measured from the same extracts. The concentration of anthocyanins was expressed as cyanidin-3-glucoside equivalents and determined spectrophotometrically at $535 \mathrm{~nm}$ using an extinction coefficient $(\varepsilon)$ of 29,600 [14]. 
Specific primers for genes encoding for the key enzymes involved in the phenylpropanoids pathway were designed (Table 1). The genes studied were: phenylalanine ammonia-lyase $(P A L)$, chalcone synthase $(C H S)$, flavonoid 3'-hydroxylase $(F 3 H)$, flavonol synthase $(F L S)$, and anthocyanin synthase (ANS). The total RNA was isolated from $100 \mathrm{mg}$ of leaves using the Spectrum Plant Total RNA Kit (Sigma-Aldrich, Milan, Italy) according to the manufacturer's instructions. The RNA concentration was assessed by NanoDrop N-1000 spectrophotometer (NanoDrop Technologies, Wilmington, DE, USA). Three $\mu$ g of RNA were reversely transcribed to cDNA using the SuperScript III cDNA Synthesis Kit according to the manufacturer's instruction (Invitrogen, Waltham, MA, USA). SYBR green chemistry was used for the quantitative reverse transcription-polymerase chain reaction (RT-PCR) analysis. Dissociation curves were performed to check the absence of primer dimers and other amplification by-products. The PCR program consisted of an initial step at $50{ }^{\circ} \mathrm{C}$ for $2 \mathrm{~min}$ followed by $95^{\circ} \mathrm{C}$ for $2 \mathrm{~min}$ and 40 cycles at $95^{\circ} \mathrm{C}$ for $15 \mathrm{~s}$ and $60^{\circ} \mathrm{C}$ for $1 \mathrm{~min}$. The expression levels were calculated using the delta-delta $C t(\Delta \Delta C t)$ method [15] on an ABI 7300 RT-PCR system (Applied Biosystems, Foster City, CA, USA), and 18S rRNA was used as reference gene.

Table 1. List of primers used for the real-time PCR analysis.

\begin{tabular}{|c|c|c|}
\hline Gene & Sequence $5^{\prime}-3^{\prime}$ & $\operatorname{Tm}\left({ }^{\circ} \mathrm{C}\right)$ \\
\hline \multirow{2}{*}{$P A L$} & forward TGTGAAGCTGGAGGAGAGA & 65.3 \\
\hline & reverse GTTTGGTCCTCCGGTGAGAG & 66.0 \\
\hline \multirow[b]{2}{*}{ CHS } & forward GGTCAAGCTCTTTTCGGGGA & 67.5 \\
\hline & reverse CGGGCGTTCTACTGACAAGT & 64.2 \\
\hline \multirow{2}{*}{$\mathrm{F} 3 \mathrm{H}$} & forward CCGGTGATCTCACTCGAAGG & 67.1 \\
\hline & reverse TTTCGCCAGCCTTGTCATCT & 67.0 \\
\hline \multirow{2}{*}{ FLS } & forward GAACAACCAGCAACCACCAC & 65.5 \\
\hline & reverse GATCCСССАTTCTCTGCTGG & 68.0 \\
\hline \multirow{2}{*}{ ANS } & forward CAACTCCGACGACCCAGAAA & 67.4 \\
\hline & reverse CCGTACCCTTGAACCTTCCC & 66.5 \\
\hline \multirow{2}{*}{$18 s R N A$} & forward GGGCATTCGTATTTCATAGTCAGAG & 60.9 \\
\hline & reverse CGGTTCTTGATTAAGAAAACATCCT & 61.4 \\
\hline
\end{tabular}

The day after harvest, leaves of 20 plants per each variety were combined and thoroughly mixed to produce bulk samples for sensory evaluation. The samples were gently rinsed under tap water and left to dry for about $15-30 \mathrm{~min}$ at room conditions $\left(22 \pm 1{ }^{\circ} \mathrm{C} ; 60 \%\right.$ relative humidity, $\left.\mathrm{RH}\right)$. For the sensory evaluation, two or three leaves of similar size and weight were selected for each variety of RE, RR, and GE. Each sample was placed in a plastic dish, properly marked with a three-digit code, and randomly assigned to the panel lists. The sensory analyses were carried out in a proper location for quality food tests close to the farm. The sensory panel group consisted of 14 trained panelists aged 20-60 years old, representing both genders, and used to consuming raw leafy vegetables at least twice a week. The adopted sensory lexicon was discussed in a session prior to the test. The sensory evaluation test was conducted in two consecutive sessions with seven panelists randomly selected. For each session, two or three pieces of leaves per each variety were randomly distributed, and all the samples were presented to each panelist simultaneously. The panelists were asked to taste the samples according to the following instructions: "taste the samples from left to right; take a bite of the cracker provided, rinse your palate with water, and wait 1 to $2 \mathrm{~min}$ before tasting the next sample; then, repeat the taste, if necessary". After the taste, the panelists were asked to evaluate each sample and to score it based on a 9-point scale (0, none; 9 , high) for each of the following attributes: visual appearance, bitterness, sourness, sweetness, and aftertaste. Moreover, the overall acceptance was performed based on a 9-point hedonistic scale. The average scores have been plotted and reported as a spiderweb graph. In addition, during the elaboration of the data, a sub-group of under-40-years-old panelists was also created with the aim to underline the differences related to age. 
All data were subjected to analysis of variance (ANOVA) followed by Tukey's multiple comparisons test. The statistics were performed using GraphPad Prism version 6 for Windows (GraphPad Software, La Jolla, CA, USA, www.graphpad.com.)

\section{Results}

\subsection{Yield}

As shown in Figure 1, all the varieties had a significantly different yield, and GE showed the highest average weight per plant. The new line, RE, showed intermediate yield value compared with RR and GE.

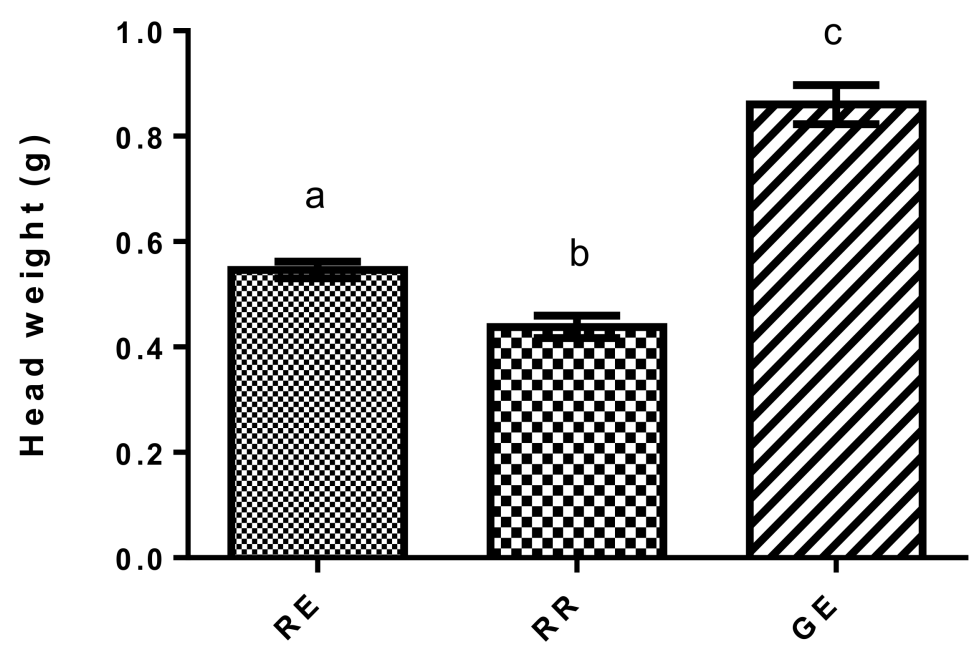

Figure 1. Yield (g/head) for red escarole (RE), red radicchio (RR), and green escarole (GE). Data are means $\pm \mathrm{SE}(n=5)$. Different letters indicate significant differences among the varieties.

\subsection{Phenolic Compounds and Anthocyanins}

To verify the presence of different compounds among RE, RR, and GE, the absorbance spectra of the three varieties were compared. The results showed that RE has an intermediate absorbance spectrum compared with RR and GE. The presence of two characteristic peaks at $336 \mathrm{~nm}$ and $418 \mathrm{~nm}$ indicate that RE may be more comparable to GE, because no peaks were observed in RR at the same wavelengths. RR showed a peak at $530 \mathrm{~nm}$, and similarly, RE showed an increment in absorbance at the same wavelength (Figure 2). The total phenols content of RE leaves showed intermediate values, but the difference was significant only compared with GE (Figure 3A). The phenolic index determined on the absorbance at $320 \mathrm{~nm}$ had the same trend (Supplementary Figure S1) and showed a significant correlation with the total phenolic concentration $\left(R^{2}=0.901\right)$ assessed with the Folin-Ciocalteau method (Supplementary Figure S2). RE showed a characteristic red coloration; this trait has been evaluated by measuring the total anthocyanin values of the methanolic extracts. The anthocyanins content expressed as cyanidin-3-glucoside in RE leaves was $34.4 \mathrm{mg} / 100 \mathrm{~g} F W$, three-fold higher than GE and 2.4 lower than red radicchio, which had significantly higher values compared to the two other varieties (Figure 3B). 


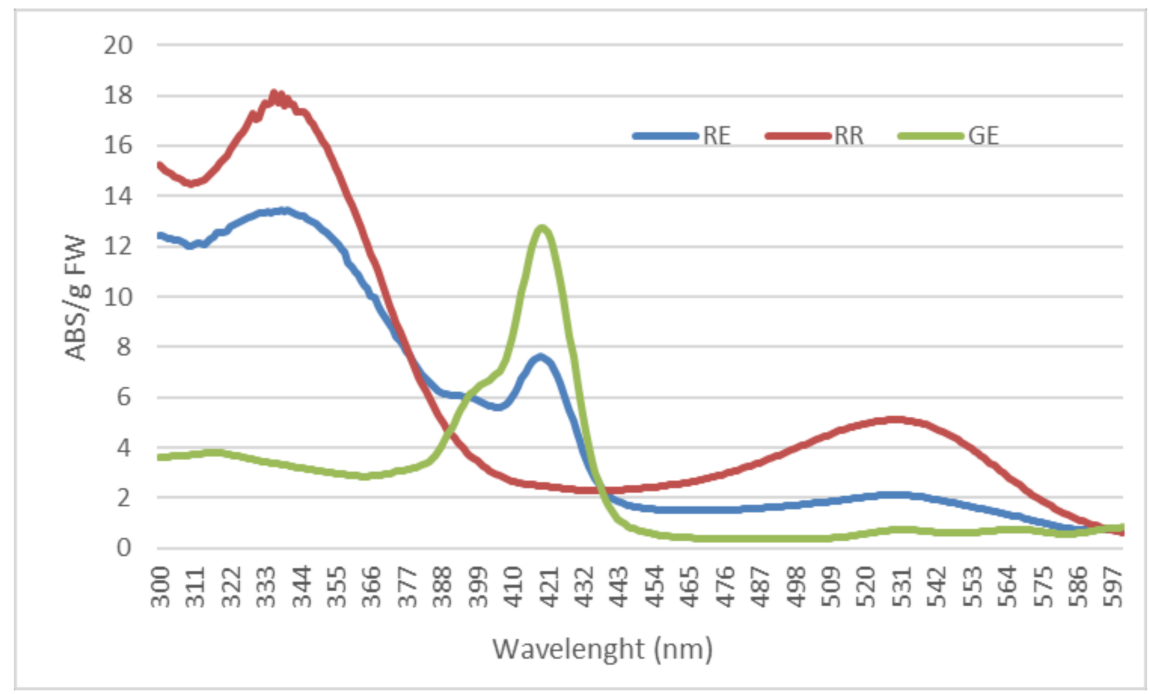

Figure 2. Comparison between UV-Vis absorbance spectra of methanolic extracts of the different varieties. Data points are means $(n=4)$.
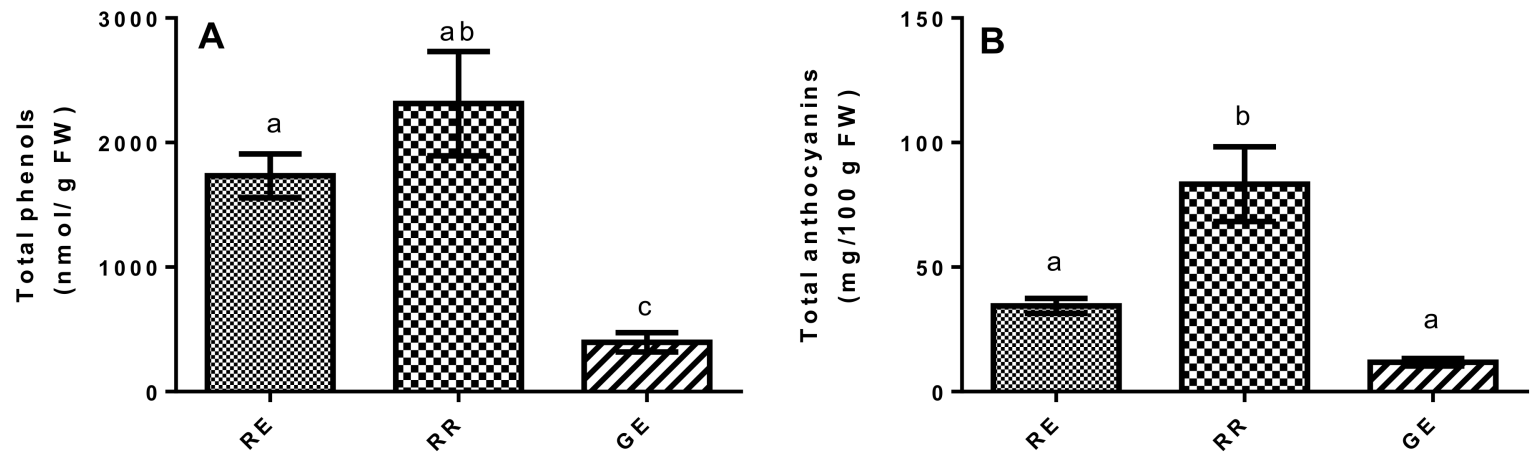

Figure 3. Total phenols (A) and total anthocyanins $(\mathbf{B})$ in the leaves of RE, RR, and GE. Data are means $\pm \mathrm{SE}(n=5)$. Different letters indicate significant differences among the varieties.

\subsection{Expression of Key Genes in the Phenylpropanoid Pathway}

In general, all the genes showed similar patterns of expression, being less expressed in RE compared with RR or GE. The expression of PAL did not show marked changes, comparing the two time points studied. RE had the lowest transcripts abundance in both cases, but at 8 a.m. it was not significantly different compared with RR (Figure 4A). In case of CHS, the pattern of expression at 8 a.m. was like that of PAL, while at 11 a.m., RR showed a marked increment in the transcripts for this gene (Figure 4B). The gene ANS showed the same pattern of expression at both timepoints, with the maximum expression recorded for GE. In both cases, RE and RR did not differ significantly. In the case of $\mathrm{F} 3 \mathrm{H}$, the trend of expression observed for the three varieties was similar to what was observed in the case of PAL with some differences. In fact, at 8 a.m., the value in RR was significantly lower than that in GE, while at 11 a.m., the expression in RE and RR increased, reaching values similar to those observed in GE (Figure 4E). Also, in case of FLS, the expression in RE increased markedly at 11 a.m., and, at this time point, it was the same as the one in RR or GE (Figure 4E). 

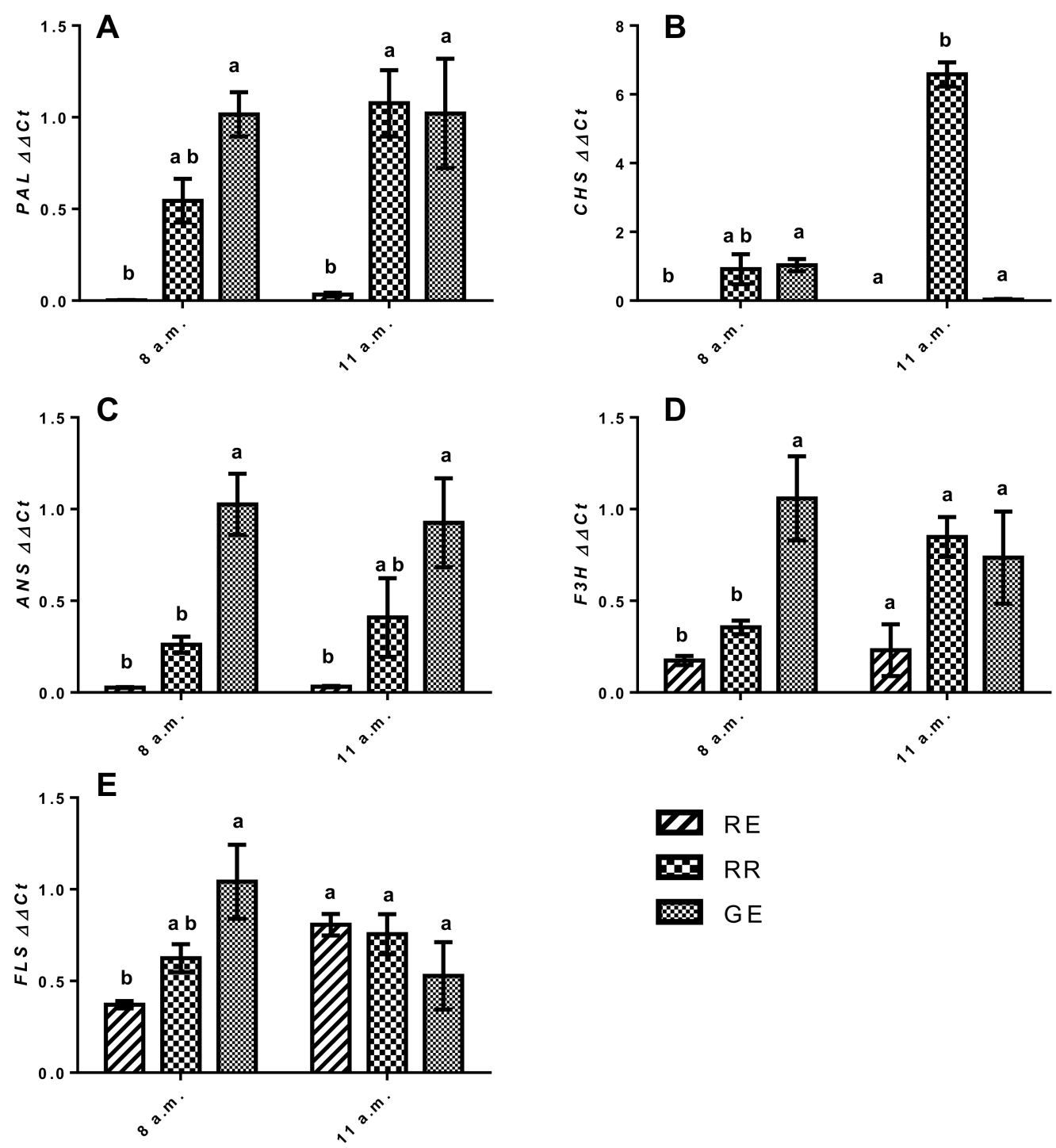

Figure 4. Expression of the key genes in the phenylpropanoid pathway measured at 8 a.m. and 11 a.m. in RE, RR, and GE. Data are means $\pm \mathrm{SE}(n=3)$. Different letters indicate significant differences among the varieties within a time point.

\subsection{Sensory Evaluation}

The data deriving from the sensory evaluation were almost the same whether considering the whole panel of evaluators (Figure 5A) or the sub-group of under-40-years-old panelists (Figure 5B). For this reason, the results will be discussed together. The new variety, RE, had the highest average score for several attributes including: visual appearance, bitterness, sourness, and aftertaste, but the differences were significant only for bitterness and aftertaste in comparison to GE. At the same time, sweetness was the lowest in RE, even though this datum was not significant. Considering the overall acceptance, all the varieties had very similar scores among them. 


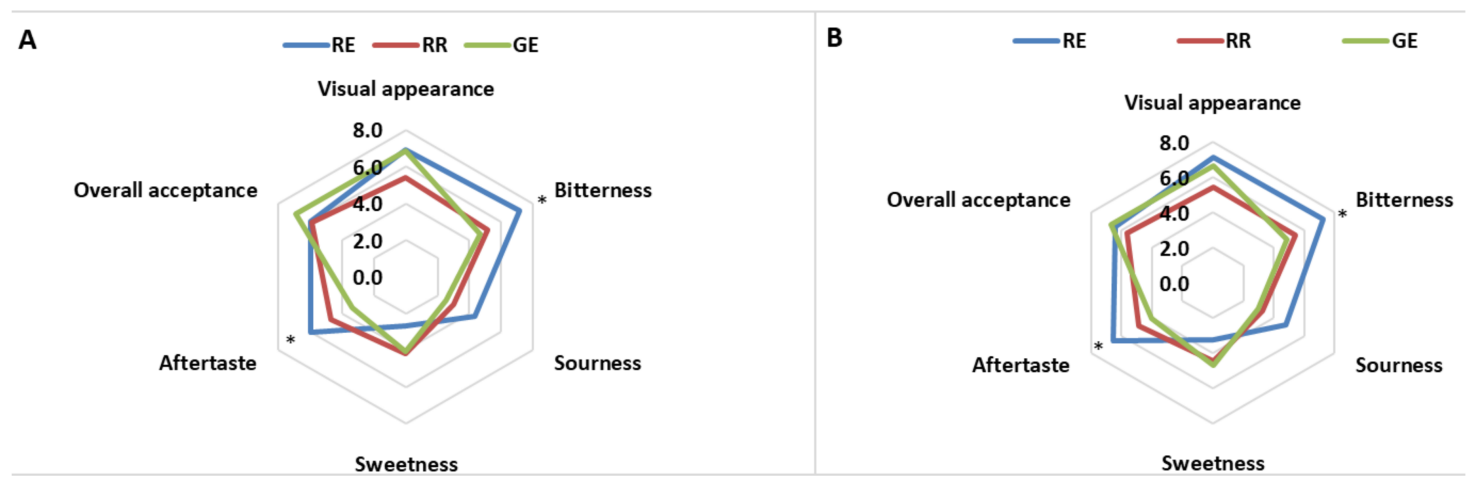

Figure 5. Sensory evaluation. (A) clustered data, (B) under 40 years old. Asterisks indicate significant differences.

\section{Discussion}

Escarole is considered to be a minor crop compared to lettuce or chicory [16], and there are few reports regarding escarole breeding improvement. In the present work, a multidisciplinary experimental approach was used to study a new variety of escarole by comparing it with its two parental lines. To the best of our knowledge, this is the first work focused on the characterization of a new variety obtained from the interspecies crossing of Cichorium endivia and Cichorium intybus. Because an interesting trait of this new line is the characteristic coloration due to the high content of anthocyanin pigments, this work focused on the possible alterations in the phenylpropanoids biosynthetic route, with specific attention to the branch of the pathway leading to the biosynthesis of flavonoids and anthocyanins. As a first observation it can be noticed that the yield recorded for RE was higher than that of RR, and even if the yield of RE was lower compared to that GE, it can be considered appropriate for commercial applications and practical use of this new variety. The comparison of the spectra was done to individuate the presence of characteristic peaks, which could indicate the presence of specific classes of molecules that could be related to important traits and thus have practical implications. The peaks observed around $330 \mathrm{~nm}$ could be related to phenolic compounds belonging to the class of hydroxycinnamic acid-derivates, glycosylated flavonols, and flavones [17]. It is interesting to observe that the new variety, RE, presented the same peak as RR, even if at a lower height, while GE did not. Also, the peak found at $530 \mathrm{~nm}$ in both RE and RR is probably an indication of the presence of anthocyanins [18]. This makes sense considering the red coloration of the leaves of the new variety, which makes it similar to RR. At the same time, it looks as if RE acquired traits typical of GE, showing a peak around $420 \mathrm{~nm}$ that was also found in GE. A maximum of absorbance in this region is typical of certain carotenoids involved in the processes of photo assimilation and chlorophyll protection (for example, neoxanthin and violaxanthin) [18]. Both RR and GE are leafy vegetables characterized by a significant content of nutraceuticals and health-related compounds [19]. It appears that important traits from RR and GE were transferred successfully to RE, which showed intermediate characteristics between its parental lines and thus can be a potential source of nutraceuticals appreciated by consumers for its health-related properties. Further investigations aiming to identify and quantify specific classes of compounds should be performed on the basis of the current knowledge of the phenolic fingerprints of the parental lines and should include the application of more accurate analytical techniques. The preliminary quantification of total phenolics and anthocyanins did in fact show that RE has intermediate values compared with RR and GE; however, this was not always supported by the statistical analysis, as the differences observed were not always significant. In comparison to other previously published works, RR showed similar [20] or lower [21,22] values of total phenolics and anthocyanins. The differences observed can be explained by considering the effect of different analytical procedures, the genetic variability, and the effect of the environment, which has been reported to be a major cause of variation [20]. The increase of the total phenols and anthocyanins in RE has the dual benefit on both consumers' health and agronomic 
management at a farm level. The higher content of these compounds could also enhance the tolerance of RE against biotic and abiotic stresses. Therefore, this new leafy vegetable can allow cultivation with lower chemical inputs, because the bioactive compounds could provide protection against several diseases [23]. RE, bringing together the characteristics of the parental lines (RR and GE), can offer the enlargement of leafy crops that can be grown during winter or in stressful cultivation areas. Previously, it has been reported in different plant species that the expression of some of the key genes in the phenylpropanoid pathway shows fluctuations during a 24-h period and appear to be controlled by a circadian clock $[24,25]$. For this reason, the expression levels of the genes studied in this work were measured at two time points, 8 a.m. and 11 a.m. Some differences in gene expression were observed between the three varieties. Often, the expression pattern in RE was similar to that in RR, while GE showed a distinct behavior. The gene CHS showed the most relevant change in expression as it was markedly up-regulated in RR at 11 a.m. This behavior is consistent with the pattern of accumulation of anthocyanins, and this correlation has been recently observed in other red leaf lettuce in response to various treatments [26,27]. Moreover, as previously showed, the increment in the CHS expression could have been triggered by the higher solar radiation at 11 a.m. Interestingly, the other genes studied showed a quite similar pattern of expression among them and no marked changes between the two time points studied. Based on these findings, it is possible to confirm a major role of CHS in RR in response to light. The development of a new variety is a complex procedure and its commercial success is tightly correlated to consumers' appreciation. Today's consumers are particularly aware of the health benefits deriving from food; at same time, sensory aspects are surely of primary importance in leading consumer choices. For these reasons, the new variety of RE was subjected to a sensory evaluation. The sensory profile obtained showed that RE was appreciated by the panelists from both groups and was considered to be as good as its parental lines with respect to most of attributes. At the same time, RE was characterized by a significantly higher bitterness and a more pronounced aftertaste compared with GE, thus showing a sensory profile more similar to RR. The bitterness is due to the presence of sesquiterpene lactones, which have been reported to be more abundant in chicory compared with escarole [28]. Further investigation on this class of compounds would help characterize the new variety of RE and support the promising results obtained in the sensory evaluation performed in the present work. RE can also be suggested as a potential vegetable for fresh-cut produce industries, because minimally processed leafy vegetables are often offered as mix of different species to provide different bioactive compounds in the diets of consumers.

\section{Conclusions}

The results showed that the inter-species crossing between RR and GE is possible and can represent a useful tool for produce innovation among the leafy vegetables. The RE encloses most of the bioactive compounds of both species and provides a new salad with high nutrition value. This new crop can be also exploited for increasing the cultivation area of vegetables and improving the salad availability even during the adverse seasons or sub-optimal environmental conditions.

Supplementary Materials: The following are available online at http:/ /www.mdpi.com/2073-4395/8/4/50/s1, Figure S1: Phenolic index in leaves of RE, RR, and GE, Figure S2: Correlation analysis between phenolic index and total phenols content determined using the Folin-Ciocalteu assay.

Author Contributions: N.A. coordinated the breeding program with the significant contribution of A.N.; N.A. and F.A. conceived of and designed the experiments; N.A., C.G., and F.A. performed the experiments; C.G. analyzed the data; N.A., C.G., and F.A. wrote the paper; and A.N., critically revised the final version of the manuscript.

Conflicts of Interest: The authors declare no conflict of interest. 


\section{References}

1. Li, Z.-H.; Wang, Q.; Ruan, X.; Pan, C.-D.; Jiang, D.-A. Phenolics and Plant Allelopathy. Molecules 2010, 15, 8933-8952. [CrossRef] [PubMed]

2. Hättenschwiler, S.; Vitousek, P.M. The role of polyphenols in terrestrial ecosystem nutrient cycling. Trends Ecol. Evol. 2000, 15, 238-243. [CrossRef]

3. Mierziak, J.; Kostyn, K.; Kulma, A. Flavonoids as important molecules of plant interactions with the environment. Molecules 2014, 19, 16240-16265. [CrossRef] [PubMed]

4. Shahidi, F.; Priyatharini, A. Phenolics and polyphenolics in foods, beverages and spices: Antioxidant activity and health effects-A review. J. Funct. Foods 2015, 18, 820-897. [CrossRef]

5. Zhang, H.; Tsao, R. Dietary polyphenols, oxidative stress and antioxidant and anti-inflammatory effects. Curr. Opin. Food Sci. 2016, 8, 33-42. [CrossRef]

6. Martins, N.; Barros, L.; Ferreira, I.C. In vivo antioxidant activity of phenolic compounds: Facts and gaps. Trends Food Sci. Technol. 2016, 48, 1-12. [CrossRef]

7. Hahlbrock, K.; Scheel, D. Physiology and molecular biology of phenylpropanoid metabolism. Annu. Rev. Plant Biol. 1989, 40, 347-369. [CrossRef]

8. Winkel-Shirley, B. Flavonoid biosynthesis. A colorful model for genetics, biochemistry, cell biology, and biotechnology. Plant Physiol. 2001, 126, 485-493. [CrossRef] [PubMed]

9. Dixon, R.A.; Achnine, L.; Kota, P.; Liu, C.J.; Reddy, M.S.; Wang, L. The phenylpropanoid pathway and plant defence-A genomics perspective. Mol. Plant Pathol. 2002, 3, 371-390. [CrossRef] [PubMed]

10. Cooke, D.; Steward, W.P.; Gescher, A.J.; Marczylo, T. Anthocyans from fruits and vegetables-does bright colour signal cancer chemopreventive activity? Eur. J. Cancer 2005, 41, 1931-1940. [CrossRef] [PubMed]

11. Kaushik, P.; Andújar, I.; Vilanova, S.; Plazas, M.; Gramazio, P.; Herraiz, F.J; Navjot, S.B.; Prohens, J. Breeding vegetables with increased content in bioactive phenolic acids. Molecules 2015, 20, 18464-18481. [CrossRef] [PubMed]

12. Ke, D.; Saltveit, M.E. Wound-induced ethylene production phenolic metabolism and susceptibility to russet spotting in Iceberg lettuce. Physiol. Plant. 1989, 76, 412-418. [CrossRef]

13. Singleton, V.L.; Orthofer, R.; Lamaela-Raventos, R.M. Analysis of total phenols and other oxidation substrates and antioxidants by means of Folin-Ciocalteu reagent. Methods Enzymol. 1999, 299, 152-178.

14. Ferrante, A.; Incrocci, L.; Maggini, R.; Serra, G.; Tognoni, F. Colour changes of fresh-cut leafy vegetables during storage. J. Food Agric. Environ. 2004, 2, 40-44.

15. Livak, K.J.; Schmittgen, T.D. Analysis of Relative Gene Expression Data Using Real-Time Quantitative PCR and the 2- $\Delta \Delta \mathrm{CT}$ Method. Methods 2001, 25, 402-408. [CrossRef] [PubMed]

16. Ryder, E.J. Lettuce, Endive and Chicory; Cab International: Wallingford, UK, 1999.

17. Lin, L.Z.; Harnly, J.; Zhang, R.W.; Fan, X.E.; Chen, H.J. Quantitation of the hydroxycinnamic acid derivatives and the glycosides of flavonols and flavones by UV absorbance after identification by LC-MS. J. Agric. Food Chem. 2012, 60, 544-553. [CrossRef] [PubMed]

18. Solovchenko, A.E.; Merzlyak, M.N. Screening of visible and UV radiation as a photoprotective mechanism in plants. Russ. J. Plant Physiol. 2008, 55, 719. [CrossRef]

19. Cefola, M.; Carbone, V.; Minasi, P.; Pace, B. Phenolic profiles and postharvest quality changes of fresh-cut radicchio (Cichorium intybus L.): Nutrient value in fresh vs. stored leaves. J. Food Compos. Anal. 2016, 51, 76-84. [CrossRef]

20. D’Acunzo, F.; Giannino, D.; Longo, V.; Ciardi, M.; Testone, G.; Mele, G.; Nicolodi, C.; Gonnella, M.; Renna, M.; Arnesi, G.; et al. Influence of cultivation sites on sterol, nitrate, total phenolic contents and antioxidant activity in endive and stem chicory edible products. Int. J. Food Sci. Nutr. 2017, 68, 52-64. [CrossRef] [PubMed]

21. D'evoli, L.; Morroni, F.; Lombardi-Boccia, G.; Lucarini, M.; Hrelia, P.; Cantelli-Forti, G.; Tarozzi, A. Red chicory (Cichorium intybus L. cultivar) as a potential source of antioxidant anthocyanins for intestinal health. Oxid. Med. Cell. Longev. 2013, 2013, 704310. [CrossRef] [PubMed]

22. Denev, P.; Petkova, N.; Ivanov, I.; Sirakov, B.; Vrancheva, R.; Pavlov, A. Determination of biologically active substances in taproot of common chicory (Cichorium intybus L.). Sci. Bull. Ser. F Biotechnol. 2014, 18, 124-129.

23. Farkas, G.L.; Kiraaly, Z. Role of phenolic compounds in the physiology of plant diseases and disease resistance. J. Phytopathol. 1962, 44, 105-150. [CrossRef] 
24. Deikman, J.; Hammer, P.E. Induction of anthocyanin accumulation by cytokinins in Arabidopsis thaliana. Plant Physiol. 1995, 108, 47-57. [CrossRef] [PubMed]

25. Cocetta, G.; Rossoni, M.; Gardana, C.; Mignani, I.; Ferrante, A.; Spinardi, A. Methyl jasmonate affects phenolic metabolism and gene expression in blueberry (Vaccinium corymbosum). Physiol. Plant. 2015, 153, 269-283. [CrossRef] [PubMed]

26. Goto, E.; Hayashi, K.; Furuyama, S.; Hikosaka, S.; Ishigami, Y. Effect of UV light on phytochemical accumulation and expression of anthocyanin biosynthesis genes in red leaf lettuce. In Proceedings of the VIII International Symposium on Light in Horticulture, East Lansing, MI, USA, 22-26 May 2016; pp. 179-186.

27. Liu, D.; Li, H.; Wang, Y.; Ying, Z.; Bian, Z.; Zhu, W.; Liu, W.; Yang, L.; Jiang, D. How Exogenous Selenium Affects Anthocyanin Accumulation and Biosynthesis-Related Gene Expression in Purple Lettuce. Pol. J. Environ. Stud. 2017, 26, 717-722. [CrossRef]

28. Ferioli, F.; Manco, M.A.; D'Antuono, L.F. Variation of sesquiterpene lactones and phenolics in chicory and endive germplasm. J. Food Compos. Anal. 2015, 39, 77-86. [CrossRef]

(C) 2018 by the authors. Licensee MDPI, Basel, Switzerland. This article is an open access article distributed under the terms and conditions of the Creative Commons Attribution (CC BY) license (http:// creativecommons.org/licenses/by/4.0/). 